https://helda.helsinki.fi

\title{
Acculturation and Identity
}

\section{Liebkind, Karmela}

Cambrigde University Press

2016

Liebkind , K , Mähönen , T A E , Varjonen , S A \& Jasinskaja-Lahti , I 2016 , Acculturation and Identity . in D L Sam \& J W Berry (eds), Cambridge Handbook of Acculturation Psychology, 2nd Edition . 2 edn , Cambrigde University Press , pp. 30-49 . https://doi.org/10.1017/CBO97813162192

http://hdl.handle.net/10138/234260

https://doi.org/10.1017/CBO9781316219218.004

acceptedVersion

Downloaded from Helda, University of Helsinki institutional repository.

This is an electronic reprint of the original article.

This reprint may differ from the original in pagination and typographic detail.

Please cite the original version. 


\section{Accepted author manuscript.}

Liebkind, K., Mähönen, T. A., Varjonen, S., \& Jasinskaja-Lahti, J. (2014). Acculturation and identity. In D. L. Sam \& J. W. Berry (Eds.). Cambridge Handbook of Acculturation Psychology. 2nd ed. (pp 30-49). Cambridge: Cambridge University Press DOI: 10.1017/CBO9781316219218

\section{CHAPTER 3}

\section{ACCULTURATION AND IDENTITY}

Authors: Karmela Liebkind, Tuuli Anna Mähönen, Sirkku Varjonen, \& Inga Jasinskaja-Lahti

Keywords: ethnic identity, national identity, religious identity, cultural identity, social identity, multiple identities, identity negotiation, identity development

\section{Introduction}

Within the framework of acculturation research, cross-cultural and social psychological studies on ethnic identities have predominantly focused on ethnic minority groups (see Liebkind, 2006, for an earlier exploration of these issues). However, all people are members of (at least) one ethnic group. Thus, questions related to the content, meaning and correlates of ethnic identity concern both majority and minority group members, just like the process of acculturation.

One source of confusion in the literature on ethnic identity is that the concepts of acculturation, ethnic and cultural identity are often operationalized and used almost interchangeably. As will be seen in this chapter, however, the strength of ethnic identification should not be confused with cultural orientation in terms of endorsement of heritage culture and/or adoption of the culture of, or participation in, the larger society, (cf. Snauwaert, Soenens, Vanbeselaere, \& Boen, 2003; Berry \& Sabatier, 2011). Indeed, 
research suggests that ethnic identity and acculturation are independent constructs. Acculturation should be conceptualized as a broader construct than ethnic identity, as it encompasses a wide range of behaviours, attitudes, and values that change with contact between cultures. In contrast, ethnic identity is that aspect of acculturation that focuses on the subjective sense of belonging to a group or culture (Phinney, Horenczyk, Liebkind, \& Vedder, 2001). It is this aspect of acculturation which is the focus of this chapter.

Almost all definitions of ethnic identity boil down to the concept of ethnicity and link ethnicity to origin. Ethnicity is primarily a sense of belonging to a particular (assumed) ancestry and an ethnic group is thought to exist whenever the belief in common descent is used to bind people together to some degree. This sense of origin is often accomplished by defining ethnicity in terms of metaphors of kinship: ethnicity is family writ large (see, e.g., Verkuyten, 2005a).

Broadly, then, ethnic identity refers to an individual's sense of self in terms of membership in a particular ethnic group. Although ethnic identity is sometimes used to refer simply to one's self-label or group affiliation, it is generally seen as embracing various aspects, such as self-identification, feelings of belongingness and commitment to a group, a sense of shared values, and attitudes towards one's own ethnic group. While ethnicity is often seen as an essential part of identity, it is important to remember that the salience of ethnicity varies situationally as well as during the lifetime of an individual. It should also be noted that ethnic identity is only one of the important social identities one has. In the context of acculturation, not only ethnic but also various cultural, religious and national identities play a crucial role. Consequently, recent research has increasingly turned its attention to the 
complex relationships and interplay between multiple identities. In mainstream psychological research, ethnic identities are typically approached through self-categorization and emotional attachment to an ethnic group, while national identities, in turn, have been studied through self-categorization and emotional attachment to the national majority or the larger society. National identity can be thus defined as an individual's sense of self in terms of membership in a particular nation or nation state (cf. e.g., Reicher \& Hopkins, 2001). In a sense, national identity is a "social fact" (Verkuyten, 2005a, p. 61), but a sense of self as a member of that category is acquired through a psychological process which gives meaning to the membership. In addition to quantitative research, various approaches within qualitative research on ethnic and national identities have contributed to our understanding of identities as socially constructed, dynamic and situationally negotiated phenomena. Thus, the view that we have on identities in the process of acculturation depends on the lens we use, i.e., the focus and approach chosen.

This chapter will first present different perspectives on and levels of analysis of ethnic and national identity. Furthermore, the conceptual distinction between different aspects of ethnic or cultural identities will be discussed. Next, the ethnic, cultural and religious content dimensions of identity will be described in more detail. After that the chapter focuses on the changes in and complexities of multiple identities in acculturation, followed by a discussion on the relationship between contextual factors, ethnic identity and well-being, paying special attention to the various consequences of experiences of discrimination. Before the concluding notes, we will also take a closer look at the discursive approach to identity negotiations. 
2. Perspectives on and levels of analysis of ethnic and national identity

Ethnic and national identities can be studied on three different levels of analysis; individual, interactive and societal (e.g., Verkuyten 2005a, 18). Psychological processes and personal characteristics are studied on the first level; here the focus can be, for example, on pride in and identification with one's ethnic group. The level of interaction is the second level; it refers to the dynamics of everyday contacts in different situations. On the third or societal level of analysis, the focus is on political, ideological, cultural, and economic features; here ethnic/national identity can be investigated, for example, in relation to legislation, dominant discourses, and inequalities between ethnic groups. Frequently social psychologists also take this level into account when they study ethnic and/or national identity, for example, when being interested in the effects of prevailing intergroup relations on identities. The second level mediates between the other two: societal relations, beliefs, norms, and values are reproduced or challenged in interaction, and it is in interactions that a sense of self and ethnic/national identity is formed. Institutionalized practices, stereotypes, and group labels at the societal level affect the way people define and position themselves through these interactions. However, people can challenge and respond to these social structures and expectations, and they actively struggle to establish and affirm their own sense of ethnic/national identity in interactions (Verkuyten, 2005a). Research may focus on the emergent and changing qualities of ethnic/national identity, but also acknowledge that people can still have a relatively stable sense of self.

The study of ethnic/national identity is characterized by many different theoretical and methodological approaches. Perspectives and levels of analyses may overlap to some extent, but to an important 
degree they are also independent of each other. One approach, typical of social, cross-cultural and acculturation psychology, can be described as socio-cognitive as it deals with the cognitive and emotional dimensions of (a relatively stable) ethnic identity. For example, within cross-cultural psychology ethnic identity is perceived to be that aspect of acculturation which concerns the subjective sense of belonging to a group or culture. The perspective of discursive psychology is rooted in social constructionist paradigm and it contributes to our understanding of identities as contextually and interactionally constructed and negotiated phenomena (see, e.g., Benwell \& Stokoe, 2006; Edwards \& Potter, 1992). These general perspectives are based on different premises and they answer different kinds of research questions. However, they complement each other and provide for a broader understanding of ethnic identity if combined than when focusing only on just one of them. Furthermore, any single study may represent more than one level of analyses (e.g., both psychological and societal), and several research methods can be used within a single perspective and level of analysis.

In a number of studies within the socio-cognitive perspective, ethnic identity is treated as being similar to any other social identity and defined simply as the ethnic component of social identity (Liebkind, 2001). Social identity theory (SIT, Tajfel, 1981) holds that people's self-image has two components: personal identity and social identity. SIT proposes that the social part of our identity derives from the groups to which we belong and is simply defined as "that part of an individual's self-concept that derives from his knowledge of his membership of a social group (or groups) together with the value and emotional significance attached to that membership" (Tajfel, 1981, p. 255). Focusing on the threat to social identity that a minority position implies, Tajfel described how, depending on the perceived 
legitimacy and stability of the social system, individuals can accept or reject a negative social identity, and how minority groups may alter the valuation of their group (Tajfel \& Turner, 1986). One reaction is simply to leave the group; members of 'inferior' groups may distance themselves physically or psychologically from their group. However, this individualistic strategy of social mobility may not be always possible, especially if the group boundaries are relatively fixed and impermeable. In cases like this, SIT suggests that a number of other avenues may be pursued, for example, to limit the comparisons made to other similar or subordinate groups, to either invent new dimensions of comparison or change the value of existing dimensions, or to confront directly the dominant group's superiority by agitating for social and economic change. Which of these tactics will be chosen depends on the prevailing social climate. If no real alternatives to the status quo are conceived, subordinate groups are unlikely to openly challenge the existing order and attempt social change.

Following this conceptualization, many studies treat ethnic minority identity primarily as an example of the more general effect of status differences between groups (Verkuyten, 2000). That is, the 'minority' aspect of ethnic minorities is considered central and membership in a minority group is supposed to pose a threat to one's self-concept. Such a threat can be counteracted by accentuating positive distinctiveness. In the Netherlands, for example, many studies (e.g., Verkuyten, 2000) have shown that ethnic identity is psychologically more salient and important for ethnic minorities than for majority group members. Furthermore, members of ethnic minority groups have been found to feel more committed to their group than majority members. According to SIT, this is a consequence of ethnic group boundaries being perceived in European nation states as relatively impermeable and intergroup status as relatively stable. As a consequence, ethnic awareness, identification and positive in-group 
evaluation among ethnic minority members are often seen as reactions to status differences and the predicaments of negative stereotypes and discrimination.

However, there is more to ethnic identity than social position, as ethnic identity is not composed simply of minority status. Treating it as such greatly limits the ability to examine and understand the richness of the meanings and experiences associated with this identity. If ethnic minority groups are treated as any low status or powerless group to which the same social psychological processes are applied, the 'ethnic' aspect is ignored and there is a failure to theorize ethnicity (e.g., Verkuyten, 2000). In an attempt to promote theorizing of ethnic identity in acculturation, Liebkind (2001) has emphasized that ethnic minority members may take a variety of positions in the face of devaluation of their group, depending on the nature of the identity threat, the specific component of identity being threatened, and the level of identification with the devalued group. Thus, according to Liebkind (2001), research on acculturation should distinguish between at least the following aspects of ethnic/cultural/social identity:

(1) Subjective (self-recognised) and objective ( other-ascribed) social/ethnic/cultural identity. Only self-recognized ingroup devaluation can result in an internalized negative ethnic/cultural identity. Even subjective perceptions of the ingroup as devalued do not necessarily threaten global self-esteem, if this devaluation is not attributed internally.

(2) Social and cultural/ethnic identity.

Devaluation which derives from specific ethnic or cultural characteristics differs from that which 
derives from socioeconomic disadvantage. Only the former can, under certain conditions, become an incentive to cultural assimilation. The latter can be an incentive to individual or collective social mobility, but is relatively independent of the former kind of devaluation. In accordance with Berry's (1997) notion of integration, acculturating individuals may wish to individually or collectively participate in the larger society, yet may not want to change their cultural identity or orientation.

(3) Degree of identification with different ethnic/cultural groups.

The degree and nature of the identification with the ethnic/cultural ingroup as well as the outgroup have to be taken into account. This includes self-categorization, strength of identification with these groups, and the degree to which the individual considers the ingroup and the outgroup to represent desirable membership groups.

The importance of making a distinction between the dimensions of ethnicity and culture in identity content will be further discussed in section 4 of this chapter.

Conceptual confusion in the ethnic identity literature may arise also if the term "social/ethnic identity" is used to refer to the content of that social or ethnic identity itself, as well as to indicate the level of identification, i.e., the strength of association with a particular group. These are essentially different components of identity, which, although related, may operate relatively independently of each other. Some researchers (e.g., Ellemers, Spears, \& Doosje, 2002) try to avoid this confusion by substituting the term "identification" with the term "commitment" and reserving the term "social identity" to refer only to the nature or content of a particular identity. This conceptual distinction may make it easier to 
understand that people may identify strongly with ( i.e., feel strongly committed to) groups that confer a negative identity upon them. Ellemers and her colleagues (2002) argue that it is precisely the level of commitment to the ingroup which will determine how individuals react to various pressures or threats towards their social identities, including their ethnic identity.

While SIT recognizes and can account for the fact that our social identity encompasses membership in several different groups simultaneously, research within this framework, like cross-cultural research on acculturation, has seldom addressed "the messier categories of social life" (Verkuyten, 2005a, p. 178), i.e., the experience of immigrants and other minority members who mix, blend and combine more than two ethnic or cultural identities, either successfully or not. There may potentially appear tensions between the ethnic, cultural, religious and/or national identities of minority members, and immigrants often develop complex identities that may undergo continual change as a function of the acculturation process (Birman, Persky, \& Chan, 2010). It is with this complexity in mind that we now turn first to examine some important dimensions of the content of the social identity of acculturating groups. After that we take a closer look at variability, complexity and change in these identities.

3. The ethnic, cultural and religious dimensions of identity

The special feature of ethnic identity in comparison to other social identities is its genealogical dimension: the notion of where we came from provides people with an important sense of an enduring identity and feelings of connectedness. Different criteria, such as physical similarities, cultural characteristics, language, religion, and historical events and myths can all play a role in the definition 
and justification of a common origin. Collective representations of the past are shaped by the present and influence present conditions, perceptions and behavior (Verkuyten, 2005a, 2014).

Subjective beliefs in common descent and history are socially constructed and therefore always subject to reinterpretations, adjustments and change. Just as all social identities depend crucially on acceptance by others, ethnic identity is sustainable to the extent that it is expressed and affirmed in social interaction (Liebkind, 1992; Verkuyten, 2005a; Verkuyten, 2014). However, although ethnic identities are malleable, they are not complete fabrications. A person's ethnicity is ascribed in the sense that one cannot choose the ethnic group into which one is born, but it is achieved to the extent that the meaning it acquires for one's total identity can be a matter of choice. The ascribed aspect of ethnicity can be played down to the extent that ethnic identity is made equal to other social identities, but transmitted as it is in primary socialization, ethnicity is often a relatively pervasive part of identity. For many ethnic minorities, continuities and obligations with former and future generations have important self-defining meanings. Questions of acceptance by one's own ethnic minority group and ingroup hassles may thus be even more stressful and problematic for ethnic minority members than the negative reactions of the majority group. Given that gender is deeply implicated in the complex of social processes and institutions devoted to ancestry, sexual coupling, procreation and care of progeny, also one's gender role may be given particularistic meanings by one's ethnicity (see e.g., Reid \& ComasDiaz, 1990; Verkuyten, 2005a).

Studying ethnic identity also raises the role of culture. Cultural differences are tied to historical experiences, some of which are based on socio-economic stratification of a relatively recent nature, 
while others are rooted in a distant past of which no one is usually conscious. This historically older cultural influence is sometimes called "deep culture", as it is embedded in language, religion and/or nationality (Liebkind, 1992). People often hold on to their ethnic group identity although their culture becomes intermingled with others. Consequently, acculturation as the process of acquiring new cultural skills does not have to imply a change of group membership and self-definition (Liebkind, 2001). Contact between ethnic groups almost always leads to an exchange of cultural characteristics and mutual adjustments, but at the same time it often results in enhanced ethnic consciousness and stronger group differentiation. Thus, as Verkuyten (2005a) has also noted, ethnic identity is not necessarily tied to culture: a sense of ethnic identity can remain strong, although cultural changes take place. That said, many ethnic groups typically put forward a limited number of cultural characteristics as representing the cultural integrity and authenticity of the group, as these cultural characteristics and practices symbolize the history and culture of the ingroup and are used to distinguish it from others. Often departures from cultural practices are typically defined as abandonment of one's own culture and betrayal of one's own people. However, ethnic identity does not necessarily have to have a distinct cultural content. Gans (1979) has used the term "symbolic ethnicity" to describe the situation where people with a long history of acculturation affiliate with an abstract collectivity which does not necessarily exist as a distinct group any more.

There is one dimension of culture, namely religion, which deserves special attention (see also Chapter 21 on the role of religion in Western Europe). Religion may in many countries play a greater role in the lives of second-generation immigrants than was the case for earlier immigrant groups, although the meaning this identity is given varies both within and between religious groups. Ricucci (2010) notes 
that assimilation theories on ethno-religious minorities in secularized contexts predict less religiosity in subsequent generations, as a result of acculturation; this is the secularization hypothesis. In contrast, conflict theories expect more religiosity in those generations because an assumed increase in perceived inter-group conflict or group threat; this is the religious mobilization hypothesis. In her own qualitative study on Moroccan (Muslim) and Filipino (Catholic) immigrant youth in Italy, Ricucci (2010) concludes that the paradoxical appeal of religion for many second-generation immigrants lies in its capacity to provide a kind of 'refuge' from their sense of marginalization and also provides positive social identity and group empowerment.

Religiosity contributes also to the hyphenated Muslim-American identity in the United States, although Muslim Americans are quite diverse in terms of ethnicity, religious practice, immigration status, and historical roots. In their study on how young Muslims negotiate their multiple immigrant identities, Sirin and Fine (2008) found that the best predictor of Muslim identity was religiosity, while the best (negative) predictors of American identity were experiences of discrimination and preference for ingroup (i.e., Muslim) social and cultural practices. Thus, in contrast to the religious mobilization hypothesis, discrimination did not have a direct effect on the immigrant youth's identification with the Muslim community, but instead weakened their American identity (Sirin \& Fine, 2008).

As discussed in more detail in the following sections, ethnic, religious and national identities can sometimes be difficult to integrate. However, this is not always the case; for example, Cieslik and Verkuyten (2006) found in their qualitative study that for the Polish Tatars, there is no inconsistency in being simultaneously Tatar and Muslim as well as Polish. The meanings given to being a Tatar and a 
Muslim were expressed symbolically and anchored in an oriental narrative which implied pride in a mythical Mongolian ancestry, while the meanings of being a Pole were anchored in facts of history. These different identities did not clash because they represented different levels of "reality". Islam was also relevant to their everyday life and the contradiction with Polishness, which is closely connected with Catholicism, was avoided by emphasizing the similarities between the two monotheistic religions and the general importance of religious commitment.

Religious identities can also be abandoned in favour of ethnic ones during the acculturation process. Jain and Forest (2004) found that Jains, a distinctive religious minority in India, acquired an ethnic identity of 'Indian' after their immigration to the United States despite having had a strong religious identity in India. Although many respondents expressed a complex relationship between their identity as Jains and their identity as Indians, the lack of critical mass for establishing their own religious institutions forced them to join temples with mixed-religion membership, which contributed to a shift from a religious (Jain versus non-Jain) to an ethnic (Indian versus non-Indian) basis for their identity (Jain \& Forest, 2004).

What can be said, therefore, is that most members of an ethnic group usually identify themselves with that group with which they have (or they think they have) a common ancestry, and they may display some distinctive cultural patterns, including religion, which acquires different meanings in different ethnic groups and social contexts. However, on the individual level self-conscious ethnic identity does not in itself imply cultural or religious distinctiveness, as both culture and religion may be in a continual process of change. Elements of culture and religion may be transformed or filled with new meaning 
and take on a new significance in the acculturation process.

4. Variability, complexity and change in ethnic identity

Traditionally, ethnic identity development has been treated as part of child's broader identity development process (see Phinney \& Baldelomar, 2011) and as taking place when children become aware of the ethnic characteristics of and differences between their ingroup and other ethnic groups. This development is influenced not only by the cognitive developmental level of the child, but also by the various social contexts surrounding the child (Umaña-Taylor et al., 2014; see also Chapter 5 on development).

Moreover, the ongoing process of identity definition is related to how we perceive both self and others; identity and intergroup processes influence each other reciprocally. According to SIT (Tajfel \& Turner, 1986), we have a need for a positive self-concept and, as a consequence, we tend to look for ways in which our own group can be favourably distinguished from other groups. This ingroup-serving tendency ("ingroup bias") can take the form of favouring one's ingroup and/or derogating outgroups. However, "ingroup love" is not always reflected in "outgroup hate" (Brewer, 1999): while some research has found strong ingroup identification to be associated with negative outgroup attitudes, other studies have suggested that strong ingroup identification provides the individual with a sense of security and makes him/her evaluate outgroups more positively. This link between a sense of security and outgroup acceptance has been called the "multiculturalism hypothesis" Berry, 2013); see also chapter 22 on multiculturalism. Research on ethnic identity development in adolescents and young adults has suggested that strong ethnic identities can constitute markers of maturity and are 
associated with less intergroup bias (e.g., Phinney, Jacoby, \& Silva, 2007, see also Chapter XX).

Research results on the correlates of ethnic identity are, however, sometimes difficult to compare with each other, because ingroup identification may be defined and measured in many different ways. For example, Roccas and her colleagues (Roccas, Sagiv, Schwartz, Halevy, \& Eidelson, 2008) have distinguished between four different dimensions of the concept of identification: importance (how much I view the group as part of who I am), commitment (how much I want to benefit the group), superiority (how much I view my group as superior to other groups), and deference (how much I honor and submit to the group's norms, symbols, and leaders). These dimensions reflect different aspects of ethnic and cultural identity and may to some extent develop and change independently of each other.

The identity processes ethnic minority members face in the process of acculturation are largely dependent on the various intergroup comparisons that are being made and their relation to each other. In multi-ethnic societies there is a variety of groups in relation to whom people define their ethnic and other social identities. The greater the number of membership groups, the greater the likelihood of the occurrence of conflict, ambiguity or other strains between them, but also the greater the possibility of alternative sources of positive identity (Liebkind, 1992; Phinney et al., 2001; Phinney, Berry, Vedder, \& Liebkind, 2006). The development of and changes in ethnic identity are part of an individual's larger identity project. Researchers have become increasingly interested in the fact that for the ethnic minority individual, multiple categories are readily available. In their case, ethnic and national identities can be thought of as two identity dimensions that vary independently, resulting in varying degrees of each within multiple identities and in- and out-group differentiation. Migrants' ethnic and national identities are seen as two dimensions of their social identity in much research 
within the SIT approach on ethnic and national identities in the context of immigration (e.g., JasinskajaLahti, Liebkind \& Solheim, 2009).

Similarly, as described in the model of acculturation strategies (see Figure 2.3 in Chapter 2), an immigrant's ethnic and national identities are thought of as two dimensions of group identity that vary independently. In line with this acculturation strategies model, an individual who retains a strong ethnic identity while also identifying with the new society is considered to have an integrated (or bicultural) identity. One who has a strong ethnic identity but does not identify with the new culture has a separated identity, while one who gives up an ethnic identity and identifies only with the new culture has an assimilated identity. The individual who identifies with neither has a marginalized identity. Identity categories and the strength of identification with them depend on a number of factors, including characteristics of immigrant groups and of the places where they have settled (Phinney et al., 2001; Phinney et al., 2006). For first-generation immigrants, change of self-label is unlikely, but for second and subsequent immigrant generations the use of a compound or bicultural label becomes more common (Phinney, 2003). However, some degree of ethnic identification may be retained in several later generations, partly because members of visible minorities are likely to be ethnically labelled by others, if not by themselves, regardless of their degree of acculturation. Another reason is that although the strength and positive valence of ethnic identity may decline from the first to the second generation, the decline is much slower in later generations. Generation is not, however, the strongest predictor of ethnic identity; ethnic identity change is strongly related to retention of ethnic cultural involvement and largely independent of orientation toward the dominant culture (Phinney, 2003). A person can, however, also identify simultaneously with multiple minority and/or 
majority groups and show various degrees of social identity complexity (Roccas \& Brewer, 2002).

Individuals may also adopt different modes of identity representation at different times, either during different periods of life or under different social conditions or or emotional states. Situational variation will be further discussed below.

When social identities do not converge, there are different ways in which the individual may structure the group representations to reconcile the competing identities (Roccas \& Brewer, 2002). Even when considering only one ethnic identity at a time, together with the national identity, the content of the resulting combined identity may include varying proportions of those two components, and these components may be either parallel or hierarchical. National identity can become a superordinate category: immigrants may perceive their own ethnic group and the national outgroup as subgroups of a common national ingroup. In order to prevent or overcome a conflictual relationship between superordinate/national and subgroup/ethnic identification, different theoretical models have been formulated. While some research has assumed that total de-categorization - playing down all group memberships - is the key to harmonious intergroup relations (e.g., Brewer, 1999), other research suggests that if members of two groups could re-categorize themselves as belonging to a single superordinate category, more favourable attitudes toward all the fellow members of the new, larger ingroup should ensue (Gaertner et al., 2008). However, both de-categorization and re-categorization may be perceived especially by minority group members to threaten their valued social identities in smaller, less inclusive groups.

The complexities related to different aspects of identity (e.g., Roccas et al., 2008; Umaña-Taylor et al., 
2014) and multiple group allegiances (e.g., Birman et al., 2010) have been highlighted recently.

Different aspects of ethnic identity (such as centrality or importance) can develop and change in different phases of life and in different situations. For example, in childhood, ethnic identity mostly concerns ethnic categorization, knowledge, and behaviours, during adolescence the focus is increasingly on affective, cognitive, and exploratory processes that attach personal meaning to the identity in question, and in young adulthood ethnic identity reflects an expansion of the life domains in which it may be relevant (Umaña-Taylor et al., 2014). Moreover, besides identifying with the two most common groups (one's own ethnic group and the mainstream society), individuals can have a sense of belonging with other groups, such as with the culture of the sending society, with a globally dispersed group of co-religionists and/or with the culturally diverse larger immigrant community in the society of settlement. This range of possible groups makes the patterns of and changes in identities even more complex. The various elements of self are arranged in a hierarchy of salience, some being in the centre of the individual's concerns, others being more peripheral. The immediate salience of identity elements may vary from one situation to another. Clément and Noels (1992) have proposed a model of situated ethnolinguistic identity. They found that feelings of ethnic group belonging vary among Francophones and Anglophones in Canada across a variety of relevant situations (Clément \& Noels, 1992) and that Chinese students in Canada feel either Chinese or Canadian - but not both simultaneously - in most situations (Noels, Pon, \& Clément, 1996). Thus, attitudes towards acculturation may not be consistent with actual behaviour and identity may not necessarily follow the same acculturation pattern as attitudes. However, the basic hierarchy between identity elements changes more slowly (Liebkind, 1992; 2001). 
The challenge faced by multiply identified individuals is not only to balance the importance of different group memberships, but rather to integrate them (Phinney \& Alipuria, 2006). Research on ethnic minority adolescents and adults alike has shown that multiple ethnic and national identities may coexist successfully (e.g., Phinney et al., 2006) but that interference between multiple central identities may be especially likely if the cultures associated with them differ (Settles, 2004). For example, Martinovic and Verkuyten (2012) found that the negative relationship between religious and national identification was strong among Turkish Muslims in Germany and the Netherlands who perceived incompatibility between Western and Islamic values and ways of life. For those Turkish immigrants who identified strongly as Muslims, higher ethnic (Turkish) identification was related to lower national (Dutch) identification, higher intergroup bias and lower endorsement of national liberal practices. In contrast, for those who did not strongly identify with Muslims, higher ethnic identification was associated with higher national identification, stronger endorsement of Dutch liberal practices, and more positive stereotypes about the Dutch outgroup.

Multiply identified individuals can claim membership in two or more groups only to the extent that they are accepted by others as members of those groups. For example, in the case of national identity, majority and minority groups may have different preferences for its content, that is, what that identity with and the relations between the subgroups within it should look like. It has been found that majority and high-status group members tend to project the characteristics of their ingroup to a common superordinate category, such as the nation (Wenzel, Mummendey, \& Waldzuz, 2007). Although both majorities and minorities may consider integration of ethnic minorities into the society as a common goal, majority members often prefer a solution where minority members would 
assimilate to the representation of the national identity held by the majority group, while minority members would prefer to keep their separate ethnic/cultural identity and develop a civic national identity (Verkuyten, 2005b). Thus, the overall context provided by the dominant group and society is crucial for how the identity patterns and adaptation of ethnic/cultural minorities develop in acculturation.

5. Identities and well-being in context

There is both cross-sectional and longitudinal research evidence showing the typicality of bicultural identity and its benefits for psychological well-being (Nguyen \& Benet-Martin25, 2013), particularly among immigrant adolescents (see, e.g., Berry, Phinney, Sam \& Vedder, 2006; Matsunaga, Hecht, Elek, \& Ndiaye, 2010). Moreover, secure and inclusive bicultural identity is associated not only with better well-being but also with more positive attitudes toward outgroups (e.g., Brewer \& Pierce, 2002). These results correspond to those obtained regarding the benefits of bilingualism (e.g., Han, 2010) and of adopting the integration strategy outlined in Chapter 2. Figure 2.3).

However, when the contributions of ethnic and national identities are included as separate variables in analyses of well-being, the results vary. For example, some studies show the separation strategy or ethnic acculturation profile (i.e. a combination of the separation strategy, ethnic identity, contact with ethnic friends and retention of the language of origin) to be related to better psychological adaptation among migrants (Berry et al., 2006; Smith \& Silva, 2011), while other studies show psychological adaptation to be more related to national identification or the assimilation acculturation profile 
(Phinney \& Devich-Navarro, 1997). One key reason for these different findings is the fact that different combinations of ethnic and national identifications are adaptive in different contexts (see, for example, Phinney et al., 2001). Some national public policy and attitude contexts support the possibility of integration and make it easier to develop a bicultural identity, while others make this resolution difficult (Jasinskaja-Lahti, Horenczyk, \& Kinunen, 2011).

Perceptions of the future and present position of the ethnic ingroup create different kinds of threats to ingroup identity. The social context provides feedback about both of these threats: information on the social position of one's group in relation to other groups and on factors related to the permeability of group boundaries, thus providing feedback on the probability of maintaining the distinctiveness of the group in the future (Ellemers et al., 2002). For non-visible minorities, the question of future vitality is intimately connected with collective survival, i.e., the threat of assimilation and the total loss of group distinctiveness. Distinctiveness threat is increased also if the numerical size of an ethnic group is perceived to be constantly diminishing as a result of the acculturation process. In the real world, distinctiveness threat often overlaps with threat to the value of social identity: minority size is frequently (though not always) associated with disadvantage in status, resources, culture and power.

Outgroups can also be a more direct source of threat to the value of one's group identity: threatening behavior can take the form of prejudice or discrimination. Branscombe and her colleagues (Branscombe, Schmitt \& Harvey, 1999; Schmitt \& Branscombe, 2002) have emphasized the importance of subjective perceptions of prejudice and discrimination for understanding the victims' reactions and psychological ramifications. As discussed in Chapter 25 perceived discrimination has a strong negative 
impact on the well-being and health of immigrants and other ethnic minority members, especially when it is pervasive and affects the individual personally (Schmitt, Branscombe, Postmes \& Garcia, 2014). Victims of prejudice and discrimination may try to rid themselves of, or attempt to conceal, their group membership. In contrast to this individual "passing" approach, such an identity threat may be coped with by adopting a more group-based strategy. Here, the role of ethnic identification becomes crucial. According to the Rejection-Identification Model (RIM; see Branscombe et al., 1999; Schmitt \& Branscombe, 2002), disadvantaged group members increasingly identify with their in-group and seek support from its members in response to prejudice. This, in turn, provides them with a sense of belonging and alleviates some of the harmful consequences of perceived discrimination. This may explain why, in some contexts, separation or ethnic cultural orientation has turned out to have an adaptive role.

The RIM has received large support in studies on ethnic discrimination, particularly among Blacks (Branscombe et al., 1999; Cronin, Levin, Branscombe, van Laar, \& Tropp, 2012) and Latin Americans (Cronin et al., 2012). This relationship was also found in the immigrant youth study (Berry, et.al., 2006), where perceived discrimination was the major factor in youth adopting the separation and marginalisation strategies, and in their having lower psychological and sociocultural adaptation. However, in some studies the expected relationship between perceived discrimination, ethnic identity, and well-being has not been obtained. For example in Finland, instead of increasing ethnic identification, Russian-speaking immigrants were found to react to perceived discrimination with disidentification from the national majority group (i.e., Jasinskaja-Lahti et al., 2009; Jasinskaja-Lahti, Mähönen, \& Ketokivi, 2012). To complement the research based on RIM, Jasinskaja-Lahti and her 
colleagues (2009; 2012) have suggested the Rejection-Dis-identification model (RDIM) according to which perceived discrimination prevents minority members from developing a sense of belonging to a national superordinate group and further leads to more negative attitudes towards the majority group members.

The choice of strategy and identity reaction to perceived discrimination are likely to depend on group characteristics, the historical intergroup context in question, and other simultaneous threats towards one's ethnic identity. It should also be noted that, as is often the case in social and behavioural sciences, causal chains are reciprocal: perceived discrimination affects identification and compromises well-being, while worsened psychological health and a strong ethnic acculturation profile predispose to less favourable perceived intergroup relations (Jasinskaja-Lahti et al., 2009; Zagefka \& Brown, 2002). In addition, the strength of ethnic identification may determine how severe the ramifications of discrimination are. The pattern of existing results is not very clear: While in some studies high ingroup identifiers have been found to be harmed more by perceived discrimination (e.g., McCoy \& Major, 2003), in others, high ingroup identification has reduced the psychological costs of discrimination (e.g., Hansen \& Sassenberg, 2006).

To summarize, according to a review by Pascoe and Richman (2009), the buffering effect of identification with a disadvantaged ingroup on health exists but it is relatively weak. Of the significant effects obtained in previous studies, around $60 \%$ indicated a beneficial, but around $40 \%$ a detrimental effect of strong ingroup identification on the relationship between perceived discrimination and health. Thus, no one theory or statistical model can fully and universally account for the complex 
interplay between ethnic identity, perceived discrimination and well-being. One way of increasing our understanding of the complexity of ethnic identity processes is to employ a qualitative approach to identity construction and identity negotiations in different intergroup contexts.

6. The discursive approach: Ethnic identity as a construction

In the previous sections we have explored ethnic identity mainly within the framework of cognitively oriented mainstream (social) psychology, which depicts ethnic identity as a measurable mental characteristic. Although widely conducted, this type of research has also been criticized for essentialism, for ignoring historical and political aspects of acculturation and identity processes and for overlooking the continuous negotiation and contestation inherent in these identity processes (Bhatia \& Ram, 2001; Howarth, Wagner, Magnusson, \& Sammut, 2014). Essentialist conceptualizations can be challenged by studying identities as complex accounts in social interactions (Verkuten \& de Wolf, 2002).

Discursively oriented qualitative research as practiced within discursive psychology, conceptualizes identities as actively constructed in talk and texts, and therefore locates them not in the world of private cognitions or experiences, but in public discourses and social interactions (Benwell \& Stokoe, $2010,83)$. Instead of asking people to fill in questionnaires to indicate which pre-defined groups they feel they belong to and how they feel about those group memberships, the discursive approach is interested in how identities are produced and negotiated in social interaction. Within this approach, research can focus on how social categories (including various ethnic identity labels) are constructed, 
how groups are discursively formed through talk and texts and how people make sense of, account for and use identities, as well as on what social functions identity constructions may have (Edwards \& Potter, 1992; Potter \& Wetherell, 1987).

Despite an abundance of discursive research on migration r-elated issues, including national identities, discursive research on how ethnic minorities construct identities is still relatively scarce. One of the earliest studies adopting a discursive perspective on ethnic minority identity was Verkuyten's (1997) study on the construction of ethnic identities among ethnic Turks living in the Netherlands. The findings showed that ethnic minority group members take an active role in defining themselves in relation to various ethnic groups (e.g. Turks and Dutch), and that self-definitions in group terms do not need to be oppositional, even though they may be divisive. Verkuyten and de Wolf (2002), in turn, examined the discursive and cultural resources used by Chinese living in the Netherlands when constructing and accounting for their ethnic identities. The discourses used by the Chinese varied in how changeable the ethnic component of their identity was depicted as. More recently, Sala and colleagues (2010) investigated the discursive construction of identity by Italian immigrants in Australia. Their study showed that while first- and 1.5-generation immigrants used different reference groups to make claims of authentic Italian identity, both groups used language, heritage and food as shared markers of authenticity. Ali and Sonn (2010), in turn, explored how Cypriot Turkish people in Australia constructed multi-hyphenated identities by using different discourses, which highlighted the current socio-political context, but also collective history. Constructions of ethnic identities are always contextual. This was also evident in the longitudinal, discursive psychological study by Varjonen, Arnold and Jasinskaja-Lahti (2013), which examined the way a group of ethnic Finnish migrants constructed 
and accounted for their ethnic identities before and after migrating from Russia to Finland. Before migration, participants mostly presented themselves as Finns, whereas after migration Finnish identity was explicitly problematized and a larger variety of self-labels was used.

\section{Concluding comments}

As has been highlighted in the previous sections, research on acculturation has moved from addressing only levels of ethnic identification toward the study of its key precursors and consequences. Importantly, both theories and empirical research have taken steps to reach a more complex understanding of multiple identities, as simple categorization into ethnic majority and minority groups cannot do justice to the increasing diversity of current societies. However, the task of unravelling the complexities of identity processes in acculturation is far from being completed. More research is needed, for example, on the dimensions and intersections of different identities. Also more qualitative research is needed in addition to social-cognitive theorizations and causal models. For example discursive psychological research on identity negotiations has provided important new information about the contents, boundaries and functions of different identity constructions.

International migration has prompted a need for identity negotiations concerning cultural maintenance vs. assimilation and the possibilities for minority group members to combine ethnic and national identities. Even though all groups involved in the process of acculturation can take part in these negotiations, minority groups have less power than majorities to influence their outcomes. Successful integration and the adoption of multiple identities can provide acculturating minority group 
members with the means for constructing situationally functional positions for themselves in relation to more than one ethnic group. In addition, as we have shown, successful management of multiple identities can have beneficial consequences for psychological well-being.

This chapter has focused on ethnic identity mainly from the viewpoint of different psychologies; acculturation, cross-cultural, social and discursive psychology. However, we acknowledge that ethnic identity has also been studied within many other disciplines. This fact may be partly responsible for some of the conceptual and methodological inconsistencies we noted above in the research on ethnic identity. However, there is also some consensus as to the role of ethnic identity in the acculturation process. First, ethnic identity seems to be conceptually distinct from other aspects of the acculturation process. Second, ethnic identity cannot be reduced to the social position of one's membership group; the meanings and relevance of ethnic identity for an individual extend beyond mere majority or minority group status. Third, the kind of ethnic identity or the combination of multiple identities which best fosters different forms of adaptation in the acculturation process is largely dependent on situational and contextual factors of the acculturating groups and the larger society. Of these factors, one of the most crucial ones is ethnic discrimination, which harms not only the psychological wellbeing of its victim, but also social cohesion and intergroup relations $\mathrm{n}$ ethnically diverse societies. While not claiming to encompass the whole variety of viewpoints on ethnic, cultural, religious and national identities, these are the three key points of this chapter.

\section{References}


Ali, L. and Sonn, C. C. (2010) Constructing identity as a second-generation Cypriot Turkish in Australia: The multi-hyphenated other. Culture \& Psychology 16(3), 416-436.

Benwell, B. \& Stokoe, E. (2010). Analysing Identity in Interaction: Contrasting Discourse, Genealogica, narrative and Conversation Analysis. In M. Wetherell \& C.T. Mohanty (Eds.), The Sage Handbook of Identities (pp. 82 - 103). London: Sage.

Berry, J. W. (1997). Immigration, acculturation and adaptation. Applied Psychology: An International Review, 46, 5-34.

Berry, J.W., Phinney, J., Sam, D., \& Vedder, P. (Eds.) (2006). Immigrant youth in cultural transition: Acculturation, identity, and adaptation across national contexts. Mahwah: Erlbaum.

Berry, J.W. \& Sabatier, C. (2011). Variations in the assessment of acculturation attitudes: Their relationships with psychological wellbeing. International Journal of Intercultural Relations, 35 _658669.

Bhatia, S., \& Ram, A. (2001). Rethinking "acculturation" in relation to diasporic cultures and postcolonial identities. Human Development, 44, 1-17.

Birman, D., Persky, I., \& Chan, W. Y. (2010). Multiple identities of Jewish immigrant adolescents from the former Soviet Union: An exploration of salience and impact of ethnic identity. International 
journal of behavioral development, 34(3), 193-205.

Bourhis, R. Y., Moise, L. C., Perreault, S., \& Senecal, S. (1997). Towards an interactive acculturation model: A social psychological approach. International Journal of Psychology, 32, 369-386.

Branscombe, N. R., Schmitt, M. T., \& Harvey, R. D. (1999). Perceiving pervasive discrimination among African Americans: Implications for group identification and well-being. Journal of Personality and Social Psychology, 77, 135-149.

Brewer, M. B. (1999). The psychology of prejudice: Ingroup love or outgroup hate? Journal of Social Issues, 55, 429-444.

Brewer, M. B., and Pierce, K. P. (2002). Social identity complexity and outgroup tolerance. Personality and Social Psychology Bulletin, 31, 428-3.

Cieslik, A., \& Verkuyten, M. National, ethnic and religious identities: Hybridity and the case of Polish Tatars. National Identities 8, 2, 77-93.

Clément, R., \& Noels, K. A. (1992). Towards a situated approach to ethnolinguistic identity: The effects of status on individuals and groups. Journal of Language and Social Psychology, 11(4), 203-232. 
Cronin, T. J., Levin, S., Branscombe, N. R., van Laar, C., \& Tropp, L. R. (2012). Ethnic identification in response to perceived discrimination protects well-being and promotes activism: A longitudinal study of Latino college students. Group Processes \& Intergroup Relations, 15(3), 393-407.

Edwards, D. and Potter, J. (1992) Discursive Psychology. London: SAGE.

Ellemers, N., Spears, R., \& Doosje, B. (2002). Self and social identity. Annual Review of Psychology, 53, 161-186.

Gans, H. J. (1979). Symbolic ethnicity: The future of ethnic groups and cultures in America*. Ethnic and racial studies, 2(1), 1-20.

Gaertner, S. L., Dovidio, J. F., Guerra, R., Rebelo, M., Monteiro, M. B., Riek, B. M., et al. (2008). The Common In-Group Model. Applications to Children and Adults. In Levy, S. R., and Killen, M. (eds.), Intergroup attitudes and relations in childhood through adulthood (pp. 204-19). Oxford, UK: Oxford University Press.

Han, W. J. (2010). Bilingualism and socioemotional well-being. Children and Youth Services Review, 32(5), 720-731. 
Hansen, N., \& Sassenberg, K. (2006). Does social identification harm or serve as a buffer? The impact of social identification on anger after experiencing social discrimination. Personality and Social Psychology Bulletin, 32(7), 983-996.

Howarth, C., Wagner, W., Magnusson, N. \& Sammut, G. (2014). “It's Only Other People Who Make Me Feel Black": Acculturation, Identity, and Agency in a Multicultural Community. Political Psychology, 35, 81-95.

Jain, N. \& Forest, B. (2004). From Religion to Ethnicity: The Identity of Immigrant and Second Generation Indian Jains in the United States. National Identities, 6, 3, 277-297.

Jasinskaja-Lahti, I., Horenczyk, G., \& Kinunen, T. (2011). Time and context in the relationship between acculturation attitudes and adaptation among Russian-speaking immigrants in Finland and Israel. Journal of Ethnic and Migration Studies, 37(9), 1423-1440.

Jasinskaja-Lahti, I., Liebkind, K., \& Solheim, E. (2009). To identify or not to identify? National disidentification as an alternative reaction to perceived ethnic discrimination. Applied Psychology, 58(1), 105-128.

Jasinskaja-Lahti, I., Mähönen, T. A., \& Ketokivi, M. (2012). The dynamics of ethnic discrimination, identities and outgroup attitudes: A pre-post longitudinal study of ethnic migrants. European Journal of Social Psychology, 42(7), 904-914. 
Liebkind, K. (1992). Ethnic identity - Challenging the boundaries of social psychology. In G. M. Breakwell (Ed.), The social psychology of identity and the self-concept (pp. 147-185). London: Academic Press.

Liebkind, K. (2001). Acculturation. In R. Brown, \& S. Gaertner (Eds.), Blackwell handbook of social psychology: Intergroup processes (pp. 386-406). Oxford: Blackwell.

Martinovic, B. and Verkuyten, M. (2012). Host national and religious identification among Turkish Muslims in Western Europe: The role of ingroup norms, perceived discrimination and value incompatibility. European Journal of Social Psychology, 42(7), 893-903.

Matsunaga, M., Hecht, M. L., Elek, E., \& Ndiaye, K. (2010). Ethnic identity development and acculturation: A longitudinal analysis of Mexican-heritage youth in the Southwest United States. Journal of cross-cultural psychology, 41(3), 410-427.

McCoy, S. K., \&, Major, B. (2003). Group identification moderates emotional responses to perceived prejudice, Personality and Social Psychology Bulletin, 9(8), 1005-17.

Nguyen, A.M., \& Benet-Martínez, V. (2013). Biculturalism and adjustment: A meta-analysis. Journal of Cross-Cultural

Psychology. 44, 122-159. 
Noels, K. A., Pon, G., \& Clément, R. (1996). Language, Identity, and Adjustment. The Role of Linguistic Self-Confidence in the Acculturation Process. Journal of Language and Social Psychology, 15(3), 246-64.

Pascoe, E. A., \& Richman, L. (2009). Perceived discrimination and health: a meta-analytic review. Psychological bulletin, 135(4), 531.

Phinney, J. S. (2003). Ethnic identity and acculturation. In K. M. Chun, P. Balls Organista, \& G. Marin (Eds.), Acculturation: Advances in theory, measurement, and applied research (pp. 63-81). Washington, DC: American Psychological Association.

Phinney, J. \& Alipuria, (2006). Multiple social categorization and identity among multiracial, multiethnic and multicultural individuals: Processes and implications In R. Crisp \& M. Hewstone (Eds.) (2006), Multiple social categorization: Processes, models, and applications (pp. 211-238). New York: Psychology Press.

Phinney, J. S., \& Baldelomar, O. A. (2011). Identity development in multiple cultural contexts. In L. Arnett Jensen (Ed.) Bridging cultural and developmental approaches to psychology: New syntheses in theory, research and policy (pp. 161-186). New York: Oxford University Press.

Phinney, J. S., Berry, J. W., Vedder, P. and Liebkind, K. (2006). The Acculturation Experience: Attitudes, Identities, and Behaviors of Immigrant Youth. In Berry, J.W., Phinney, J. S., Sam, D. L. and Vedder, 
P. (eds.). Immigrant Youth in Cultural Transition. Acculturation, Identity and Adaptation Across National Contexts (pp. 71-116). Mahwah, NJ: Lawrence Erlbaum Associates.

Phinney, J. S., \& Devich-Navarro, M. (1997). Variations in bicultural identification among African American and Mexican American adolescents. Journal of Research on Adolescence, 7, 3-32.

Phinney, J. S., Horenczyk, G., Liebkind, K., \& Vedder, P. (2001). Ethnic identity, immigration, and wellbeing: An interactional perspective. Journal of Social Issues, 57, 493-510.

Phinney, J. S., Jacoby, B. and Silva, C. (2007). Positive intergroup attitudes: The role of ethnic identity . International Journal of Behavioral Development, 31, 478-90.

Potter, J. and Wetherell, M. (1987) Discourse and Social Psychology: Beyond Attitudes and Behaviour. London: SAGE.

Reid, P. T., \& Comas-Diaz, L. (1990). Gender and ethnicity: Perspectives on dual status. Sex Roles, 22(78), 397-408.

Reicher, S., \& Hopkins, N. (2001). Self and nation. London: Sage.

Ricucci, R. (2010) Religion and Adolescent Immigrants in Italy: A Case of Identifying with or Turning away from their Communities. Journal of Contemporary Religion, 25,3, 419-436. 
Roccas, S. and Brewer, M. B. (2002): Social identity complexity. Personality and Social Psychology Review, 6, 88-106.

Roccas, S., Sagiv, L., Schwartz, S., Halevy, N., \& Eidelson, R. (2008). Toward a unifying model of identification with groups: Integrating theoretical perspectives. Personality and Social Psychology Review, 12, 280-306.

Sala, E., Dandy, J. and Rapley, M. (2010) 'Real Italians and Wogs': The discursive construction of Italian identity among first generation Italian immigrants in Western Australia. Journal of Community and Applied Social Psychology 20(2), 110-124.

Settles, I. H. (2004). When multiple identities interfere: The role of identity centrality. Personality and Social Psychology Bulletin, 30, 487-500.

Schmitt, M. T., \& Branscombe, N. R. (2002). The meaning and consequences of perceived discrimination in disadvantaged and privileged social groups. In W. Stroebe, \& M. Hewstone (Eds.), European Review of Social Psychology, vol. 12 (pp. 167-199). Chichester: John Wiley \& Sons.

Schmitt, M. T., Branscombe, N. R., Postmes, T., \& Garcia, A. (2014). The Consequences of Perceived Discrimination for Psychological Well-Being: A Meta-Analytic Review. Psychological Bulletin, 140(4), 921-948. 
Sirin, S. R., \& Fine , M. (2008). Muslim American Youth: Understanding hyphenated identities through multiple methods. New York: NYU Press.

Snauwaert, B., Soenens, B., Vanbeselaere, N., \& Boen, F. (2003). When integration does not necessarily imply integration. Different conceptualizations of acculturation orientations lead to different classifications. Journal of Cross-Cultural Psychology, 34, 231-239.

Tajfel, H. (1981). Human groups and social categories. Cambridge: Cambridge University Press.

Tajfel, H., \& Turner, J. C. (1986). The social identity theory of intergroup behaviour. In S. Worchel, \& W. Austin (Eds.), Psychology of intergroup relations ( $2^{\text {nd }}$ ed., pp. 7-24). Chicago: Nelson-Hall.

Umaña-Taylor, A. J., Quintana, S. M., Lee, R. M., Cross, W. E., Rivas-Drake, D., Schwartz, S. J., Syed, M., Yip, T., Seaton, E. and Ethnic and Racial Identity in the 21st Century Study Group (2014). Ethnic and racial identity during adolescence and into young adulthood: An integrated conceptualization. Child Development, 85, 21-39.

Varjonen, S., Arnold, L. and Jasinskaja-Lahti, I. (2013). We're Finns here, and Russians there': A longitudinal study on ethnic identity construction in the context of ethnic migration. Discourse \& Society, 24, 110-134 
Verkuyten, M. (1997). Discourses of ethnic minority identity. British Journal of Social Psychology, 36, 565-685.

Verkuyten, M. (2000). The benefits to social psychology of studying ethnic minorities. European Bulletin of Social Psychology, 12(3), 5-21.

Verkuyten, M. (2005a). The social psychology of ethnic identity. London: Psychology Press.

Verkuyten, M. (2005b). Ethnic group identification and group evaluation among minority and majority groups: testing the multiculturalism hypothesis. Journal of personality and social psychology, 88(1), 121.

Verkuyten, M. (2014). Identity and cultural diversity: What Social Psychology can teach us. London: Routledge.

Verkuyten, M. and de Wolf, A, (2002). Being, Feeling and Doing: Discourses and Ethnic Self-Definitions among Minority Group Members. Culture and Psychology, 8, 371-399.

Wenzel, M., Mummendey, A., \& Waldzus, S. (2007). Superordinate identities and intergroup conflict: The ingroup projection model. European Review of Social Psychology, 18(1), 331-372.

Zagefka, H., \& Brown, R. (2002). The relationship between acculturation strategies, relative fit and 
intergroup relations: immigrant-majority relations in Germany. European Journal of Social Psychology, 32(2), 171-188. 